\title{
Views on Creativity, Environmental Sustainability and Their Integrated Development
}

\author{
Vivian M. Y. Cheng \\ Education University of Hong Kong, Hong Kong, China \\ Email: vcheng@eduhk.hk
}

How to cite this paper: Cheng, V. M. Y. (2018). Views on Creativity, Environmental Sustainability and Their Integrated Development. Creative Education, 9, 719-743. https://doi.org/10.4236/ce.2018.95054

Received: March 12, 2018

Accepted: April 21, 2018

Published: April 24, 2018

Copyright $\odot 2018$ by author and Scientific Research Publishing Inc. This work is licensed under the Creative Commons Attribution International License (CC BY 4.0).

http://creativecommons.org/licenses/by/4.0/

\begin{abstract}
In the modern paradigm of sustainability, the role of creativity is of growing significance. No literature was found to have explored the relationship of creativity and environmental sustainability, in the perspective of university students. It is unsure-how our university students perceive them, especially for students of different backgrounds. This study aims at investigating the views of university students on human creativity (HC) and environmental sustainability (ES), and how these two views might affect their supportiveness and understanding of HC-ES integrated development. Case studies of four university students were conducted. They were carefully chosen in an education university of Hong Kong, a place where east-west culture meets. The Self-determination Theory and the Four-C Creativity Model were adopted to frame this study and to analyze its data. Two rounds of interview were conducted with interview scripts transcribed for content analysis. Results showed that the university students hold quite diverse views on HC, ES and HC-ES relationships. The students with general creativity training and/or authentic experiences in $\mathrm{ES} / \mathrm{HC}$ were found to adopt a little-C and mini-C creativity conception and a self-determined ES approach, which subsequently bought a greater support to HC-ES integrated development/education. Based on the present findings, creativity training is recommended to environmental or sustainability programme in university education. Adopted the case study method, the present research has finally revealed the complexity of this seemingly simple issue, and paves the way for future creative environmental development and its research studies.
\end{abstract}

\section{Keywords}

Creativity, Environmental Sustainability, Integration, Views, University Students 


\section{Introduction}

Creativity and Sustainability are two important developments of mankind. There are numerous studies on environmental/sustainable education or on creativity training, however, studies on these two subjects together are rarely found. In academic field, human creativity (HC) and environmental sustainability (ES) are two trees far apart in the forest. Integration of their developments is surely an under-researched topic (Daskolia et al., 2012; Sandri, 2013). Is it possible for HC and ES development to have any synergetic effects on each other? What are the views of university students on them and how these views affect their support to creative environmental education? The present study is set out to answer these questions and to fill up the above research gap. In this study, environmental sustainability (ES) generally refers to a combination of both environmental conservation and sustainable development of mankind.

For a long period, acquiring knowledge of the environmental facts has been considered a prerequisite for performing environmental attitudes and behaviors (Esa, 2010; Pe'er et al., 2007). On the contrary, an increasing number of studies reported that increasing environmental knowledge may not bring more pro-E Sbehavior (Kuhlemeier et al., 1999; Levine \& Strube, 2012; Otto et al., 2016). Quite a number of studies highlight that creativity has a significant role in a person's pro-E Scompetencies and in the execution of ES practices or lifestyle (Corral-Verdugo et al., 2015; Fraj \& Martinez, 2006; Sandri, 2013). In current school curriculum, environmental programs mainly emphasize on knowledge and value learning but put little attention on fostering student creativity in this area (Sandri, 2013). Even though some studies did slightly touch on creativity/creative thinking in environmental education, most of them focused on student creative arts (Gray et al., 2016; Homfray, 2012; Sang, 2010; Silo \& Khudu-Petersen, 2016). A few other studies contributed to creative teaching and learning in this area (Barbier et al., 2009; Daskolia \& Kynigos, 2012; Scoffham, 2013). Fostering creativity in ES probably never is a key agenda in education field. The present explorative study set out to explore university students' views on this issue, and looks forward to reforming creativity education and environmental education.

\subsection{Self-Determination Theory, Creativity and Pro-ES Behaviors}

According to self-determination theory (SDT, Ryan \& Deci, 2000), individual's behavior is considered as self-motivated and self-determined. Personal interest, enjoyment, inherent satisfaction regulated ones' motivation. These intrinsic motives (instead of extrinsic ones) play a dominant role in one's life-long habits and behaviors. According to Deci \& Ryan (2008), the innate psychological needs which motivate the person's behaviors include the need for competence, autonomy, and social relatedness. Therefore, fulfillments in these three aspects will create intrinsic motivation for self-determining behaviors.

In line with the self-determination theory, Hines, Hungerford, \& Tomera 
(1987) modeled a range of attributes to pro-ES behaviors, highlighting the significance of several self-motivating factors (e.g. interest, locus of control, personal responsibility, action skills, knowledge of issues, knowledge of action strategies, and intention to act). Among these factors, intention to act is considered as the most critical construct (Karaarslan et al., 2014), and intention to act is self-determined (Darner, 2009). Karaarslan et al. (2014) further concluded that pre-service teachers' motivation toward conducting pro-ES activities were intrinsically motivated. Individuals took action for intrinsic reasons, not for instrumental factors, such as obtaining tangible rewards or avoiding a feeling of guilty. The significance of self-determination in pro-ES behaviors was further emphasized in several other studies (De Groot \& Steg, 2010; Karaarslan et al., 2014; Van der Werff et al., 2013).

The self-determination approach coincides with Maslow's self-actualization theory of human creativity (1968). In this theory, creativity is widely considered as a self-actualizing process, fulfilling human basic needs. The creative process will bring about optimal happiness (named as "flow" experience) and long-lasting intrinsic motivation to creators (Csikszentmihalyi, 1996). Experience of engaging in creative activities or creativity training was found to have positive impacts on working effects, learning motivation, confidence, self-concept, resilience, subjective well-being, and the positive psychology of learners (Amabile et al., 2005; Jindal-Snape et al., 2013; Sellman, 2012). These positive psychological outcomes are in contrast to the negative emotions of fear, guilt and shame which were usually provoked in traditional environmental education (Fretwell, 2009; Strife, 2012; Tabone, 2011). In recent years, a positive psychology movement has emerged in the environmental field (Corral-Verdugo, 2012; Ojala, 2012). Studies (Bechtel \& Corral-Verdugo, 2010; Brown \& Kasser, 2005; Corral-Verdugo, 2012) revealed that happiness and psychological well-being had reciprocal relationships with pro-ES behaviors. Scoffham and Jonathan (2011) further suggested for creativity-conducive pedagogies to promote learning happiness in ES issues. Based on these literatures, the present study expected that engaging in creative tasks can enhance the positive effects of environmental learning by improving the happiness, intrinsic motivation and other positive psychological characteristics in people.

Furthermore, in self-determination theory, fulfillments in the needs of competence and autonomy will also bring self-motivated behaviors. Competent individuals generally believe that they have the capacity to action. If the need for competence is not fulfilled, negative self-beliefs and a feeling a-motivated will be developed (Darner, 2009, 2012). Personal competence and autonomy is closely related with his/her creativity. A person with higher creativity in certain task is more likely to perceive higher competence and autonomy in that task (Chang, Hwang, \& Choi, 2012; Deci \& Ryan, 2008). Therefore, we expect creativity in pro-ES practices will bring feeling of competence and autonomy, which in turn motivates further pursuits in ES. 


\subsection{Further Connection of Human Creativity (HC) and Environmental Sustainability (ES)}

In the new paradigm of sustainability, Corral-Verdugo et al. (2009) recognized a variety of human-nature interactions and they interpreted that "Sustainability is more dynamically comprehensive, more open to ...changes (p.34)". In other words, there is no fixed path to achieve sustainability and it is subject to human creativity. A few scholars recognize the connected relationship of sustainability and creativity, especially for societal development. Clemente (2009) notes that sustainability and creativity have always appeared in urban design with a synergizing relationship. Iannarone (2008) suggested that we should cultivate creativity and wisdom in practice and in theory as well so as to plan for sustainability. Albrechts (2010) perceived creativity to be a force to drive the society toward sustainability through its capacity of imagining and visioning.

At individual level, Corral-Verdugo et al. (2015) suggested that creativity is an essential component of pro-environmental/sustainable competency. They also stressed that curiosity stimulates the construction of knowledge, expertise, and environmental skills, where as open-mindedness could help in breaking the barriersthat hold individuals up to develop more sustainable lifestyles. Hedlund-de Witt et al. (2014) stressed that "inner growth and spirituality...(that are) conducive to connectedness with nature and willingness to change" could bring about personal sustainable lifestyle. Paletz et al. (2013) revealed that reuse and recycle were closely related to the adaptive creativity and novelty in the domains. Lewis (2012) also highlighted the need of promoting creativity in realizing eco-lifestyles. In short, literature informed us that human creativity may be closely connected with ES practices, at both individual and societal levels.

In educational field, both Sandri (2013) and Sterling (2009) have argued for the important role and value of creativity in the environmental/sustainable education. As innovative capabilities are needed in dealing with the future challenges, creativity in learning process and outcome both are cardinal for the paradigm change to be effective (Sterling, 2009). Foster (2011) explicitly proposed that ES education demands active learning that involves exploratory-creative commitment and a robust tolerance for uncertainty. A study of Daskolia et al. (2012) revealed that teacher-participants conceptualized creative thinking as an inherent part of environmental problem-solving. The conventional instrumental knowledge learning may no longer viable in the new educational model for sustainability. Creative thinking and creative problem solving should be a necessary and significant component of modern environmental/sustainable education (Disinger, 1990).

\subsection{Four-C Model of Creativity and Environmental Sustainability} (ES)

Despite the above literature and arguments, developing student creativity for ES is certainly a new value/topic to many educators. They may wonder that-isn't 
creativity only that for the gifted or in artistic domains. Yet, in academic field, creativity is well-received as a natural human need and competencies (Beghetto, 2010; Maslow, 1968). Everybody can develop creativity, and creativity can be displayed in ordinary and everyday operation and performance. Creative ideas can happen anywhere and anytime. Someone can be creative in science or mathematics disciplines, as same as in music or dance. Robinson \& Azzam (2009) explain that "creativity is a process of having original ideas that have value and being creative is looking for new ways of doing things in whatever you do ( $\mathrm{p}$. $22)$ ". This ordinary everyday creativity that may not generate any product-outcome but may only involve being imaginative and going beyond the obvious patterns (Craft, 2001). In line with these creativity theories, Daskolia et al. (2012) defined creativity in environmental education to be "a kind of novel understanding, an idea, a practical solution, or a meaningful product".

In scholastic definition, creativity is defined in two criteria, novelty/originality and usefulness/appropriateness (Runco \& Jaeger, 2012). Creativity in ES refers to generating novel/original and useful/appropriate ideas for actualizing ES. Kaufmann \& Beghetto (2013a) pointed out that there are various types and levels of creativity. They proposed a Four-C Model of Creativity on a creativity developmental trajectory (Beghetto \& Kaufman, 2014). The four types are the eminent Big-C (represented a genius-level creativity), the Pro-C (represented an expert-level creativity), the Little-C (for everyday expressions of creativity), and the Mini-C (for the subjective self-discoveries and insights in the learning process). Since actualizing the 4 Rs(i.e. recycling, reuse, reduce, replace) demands creative problem solving in daily-life (i.e. little-C); and understanding ES requires an ability for construction of meaning (i.e. mini-C). Thus, the actualization of ES of common university students are expected to be related to their mini-C and little-C creativity.

\subsection{Creativity Development and Education}

The development of these four types of creativity is not discrete from each other. Mini-C creativity is the origin for any creative achievement, fertilizing Little-C and also Prof-C (Beghetto \& Kaufman, 2007; Kaufman \& Beghetto, 2009). Pro-C performed in a discipline that requires skill, knowledge, and control (Robinson \& Azzam, 2009). For the difference between Pro-C and Little-C, the former involves the deliberate practice in expertise, and but the latter does not (Kaufman \& Beghetto, 2013a). Glaveanu (2011) argues that the Little-C creativity is an everyday experience, and education is a way to move Little-C up to Pro-C.

Currently, Hong Kong educators lack confidence in implementing the creativity-fostering curriculum because most of them have no relevant training (Cheng, 2011; Davis \& Krjcik, 2005; Hui et al., 2015). Inexperience in creativity may cause misconception of creativity, adopting only Big-C conception (Cheng, 2016). The bias of Big-C conception (Beghetto, 2010) in people's mind implies 
an over-emphasis on creative eminence which may result in giving-up of teaching creativity. As long as educators failed to recognize the importance of the other three types of creativity, they tended to resist adopting creativity teaching in ordinary classrooms for all students and to constrain creativity teaching for a small group of identified gifted students. While conventional teaching approach in environment education emphasizes knowledge and values in environmental issues, creativity has not been formally covered in the subject. Even though a few literatures were found around this topic, yet, the integration of creativity and environmental education is rarely implemented in real-life classroom (Sandri, 2013).

\section{Method}

\subsection{Case Study Approach}

The present study targets at understanding the possible kinds of views university students might have on ES, HC, their relationships and their integrated education, and how their views might be interrelated with each other and their backgrounds. Qualitative case study method was chosen to achieve this goalas this study is a new research area with needs of exploration for theory development (Eisenhardt, 1989; Eisenhardt \& Graebner, 2007; George \& Bennett, 2005) and understanding the current phenomenon from different viewpoints (Baxter \& Jack, 2008; George \& Bennett, 2005; Schell, 1992; Kohlbacher, 2007; Yin, 1994). Creswell (2015) interpreted that a case study "is an in-depth exploration of a bounded system (e.g. an activity, event, process, or individuals) based on extensive data collection" (p. 469). Corbin \& Strauss (2008) further elaborated that case study brings "the descriptive details that add the richness and variation, which demonstrate the complexity of human life, thus lift the findings out of the realm of the ordinary" (pp. 13-14). Although the qualitative data covers unlimited numbers of variables within the context of phenomenon, the case study cannot provide a general conclusion (Yin, 1984; Zainal, 2007). Nevertheless, a quality qualitative research should "resonate" with readers' and participants' life experience... which provides substance, gives insight, and shows sensitivity (Corbin \& Strauss, 2015). These literatures had spelled out why case study method was adopted. The present study targets at exploring the richness and variations in university students' views, so as to enhance readers the sensitivity and insights to this blend new issue (i.e. the integration of HC and ES in education) in a complicated system (including activity, event, process, and individuals) as its research context.

\subsection{Research Context}

The present study was conducted in a modern China city, Hong Kong. It is a former British colony for 156 years and is well-known as a meeting place of east-west cultures. In recent years, its government had initiated creativity education reforms (Hui \& Lau, 2010). However, its culture in education is still rather 
conservative, dominated by examination-orientated and rote learning with limited creative teaching and learning in real-life classroom (Cheng, 2010). On the other hand, environmental education is also an emphasis in school curriculum. It is formally integrated into Sciences, General Studies, and other school subjects. However, its teaching approach is rather knowledge-dominated, focusing on informing students the harms mankind had done to the Earth, and persuading students to adopt some government-set rules to achieve $4 \mathrm{Rs}$ in daily-life. For understanding the views of university students, the present study was conducted in The Education University of Hong Kong. This university is recently ranked second in teacher education in Asia by Quacquarelli Symonds (QS) World University Rankings

(https://www.topuniversities.com/university-rankings/university-subject-rankin gs/2018/education-training). The university-trained teachers for local kindergarten, primary and secondary schools in its $4 / 5$-year degree programmes. Of course, university student views are likely to be influenced by their cultural and educational backgrounds. It is impossible to reveal all possible views on $\mathrm{HC}$ and ES by a single study. In order to gain a broader and more dynamic understanding of the issue, this study chose a context of mixed cultures and educational changes for research. Furthermore, at the time of this study, most curricula in this university did not cover creativity or creative thinking, but the university has already had a newly established standalone minor, titled "Creativity", for all students to take. At that period of time, this Creativity Minor did not study anything related to environmental sustainability. It only covered creativity training in arts, sciences, teaching and independent projects. Choosing samples in this university allows us to study the differences between university students who had and had not received creativity training.

\subsection{Sampling}

The study used the purposive sampling method to select participants. Frequently used in qualitative studies, this method selects samples based on characteristics of a population and the purpose of the study (Creswell, 2015; Patton, 2002). To fit for the purpose of the present study, four university students (Interviewee A, $\mathrm{B}, \mathrm{C}$ and $\mathrm{D}$ ), that had substantial understanding of ES education but different creativity backgrounds, were selected to be sample of the case studies. They are all Chinese females, aged in twenties, studying the last year of the Bachelor of Education programme in Education University of Hong Kong. They majored in General Studies (GS), which is a teaching subject in local primary school that had integrated science, health, social and environmental studies. Though respondents had the same major, they minored in different subjects-Interviewee A minored in sustainability; Interviewee B minored in music; both Interviewee C and $\mathrm{D}$ minored in creativity. At the time of the interviews, respondents had already completed their teaching practices in schools and most studies in their majors and minors (including studies in environmental protection, sustainability 
and creativity, if any). This group of samples was chosen first because university students of GS major have substantial trainings in environmental education. They should have certain understanding and commitment to environmental education. Yet, since they had different minor studies, this study could explore how their views diversified, and in what ways these views were related to their different learning backgrounds and experiences. About $80 \%$ of university students in that GS major were females.

\subsection{Data Collection and Analysis}

Two semi-structural interviews were conducted to each interviewee. First interview focused on their views on human creativity (HC), environmental sustainability (ES) and the HC-ES relationships. Questions asked included: What you usually associate with creativity? what you think creativity is? Do you think you are a creative person, in what way you are or are not? Do you have any creativity learning or daily-life experiences? If yes, please quote your most impressive ones. Similar questions were asked around ES. For understanding views on HC-ES relationship, the interview questions included: Have you ever thought about the relationships of $H C$ and ES, what are your prior views on them? At present, do you think $H C$ affects ES, in what way it does? Does ES also affect $H C$, in what way it does? Should these two types of human development be integrated? Why and how? To avoid creating strong prime effects or overloading respondents, a second interview was scheduled about one month later. It focused on asking interviewees their views on creativity education, environmental education and their integration. The interview questions are: Do you like to teach creativity/environmental education? Why and how? Do you think creativity-fostering learning elements should be infused into environmental/sustainable education? Why and how? On the other hand, should ES be used as a domain of creativity training? Why and how? Do you support an in-depth integration of HC-ES education? Why and how it looks like? Apart from these structured questions, other follow-up or improvised questions were asked in these semi-structured interviews.

All interviews were conducted in Chinese, the native language of participants, and each one lasted about 50 minutes. All interviews were recorded with the consent of the participants. The interview recordings were then transcribed verbatim in written scripts, from which the interview contents were then translated into English. Through inductive content analysis, the scripts were first classified according the pre-designed four themes (i.e. views on HC, views on ES, views on HC-ES relationships and views on HC-ES education). Then, each sub-theme of the responses identified from the interview scripts were assigned a unique code for further analysis. The process of the coding method, comparison and clustering responses was based on the method outlined by Miles \& Huberman (1994). Two researcher members conducted the data analysis independently. For any discrepancies arise, they listened the original audio recordings to prove the cor- 
rect meaning of the responses and negotiated to seek final agreements.

\section{Results}

The four university students exhibited diverse views on human creativity (HC), environmental sustainability (ES), HC-ES relationships and integrated HC-ES education, which were reported and analyzed in paragraphs below. Table 1 shows a summary of their views.

\subsection{Case Study of Interviewee A}

Backgrounds. Interviewee A was a Chinese female, majored in General Studies, minored in sustainability, and was studying the last semester of the Bachelor of Education programme, at the time of the interview. She reported that she had no specific backgrounds in creativity and had not received any formal or informal

Table 1. Summary of the four cases.

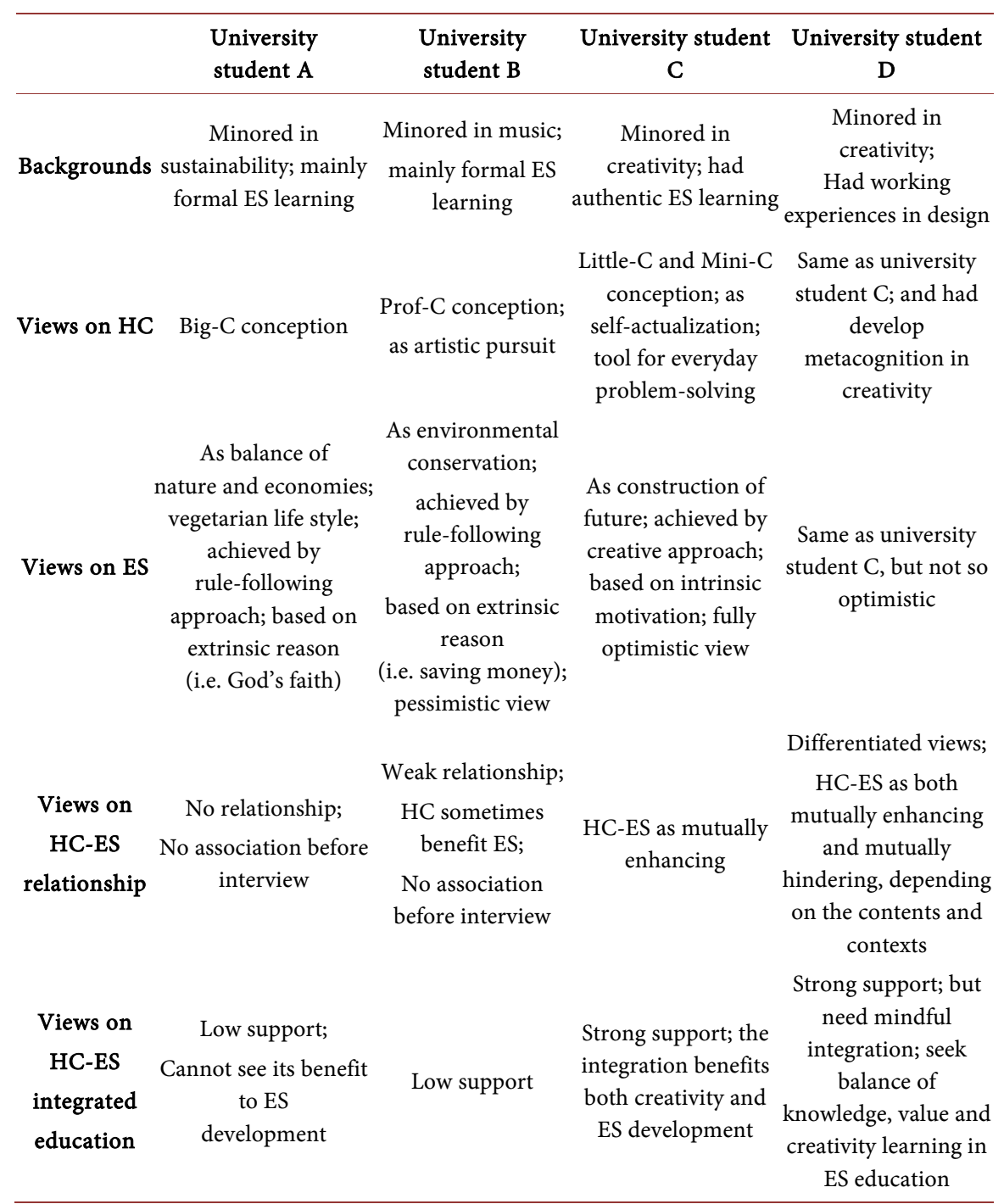

Note. "HC" represents human creativity; "ES" represents environmental sustainability. 
creativity training. She felt that the ES learnings in her secondary geography courses and that in the sustainability courses of the university were most impressive. One special characteristic of her-she was a vegetarian and she enrolled herself in some organic gardening courses. She was also strongly dedicated to her religion as much as being a vegetarian.

Views on HC. Interviewee A believed that creativity was a quality of which only a few were born with it, and a creative genius is not that can be taught by teachers. She thought that in her she never had that quality. She explicitly stated that she was not a creative person. Obviously, Interviewee A took a Big-C conception of creativity.

Views on ES. Interviewee A did show a strong concern about ES. She referred ES to the well-being of both economies and nature. In her words, economies must continue to develop under the priority of conserving nature. In this regard, her conception of ES was not limited to environmental protection, but a dynamic view of balance. Yet, she adopted a rather "rule-following" approach in achieving ES. She believed that her vegetarian diet would contribute to the ecological balance: "P $m$ surely a pro-ES person. Being a vegetarian can help to protect the nature... Like this-to make room for animal farms for raising livestock, businesspersons remove forests... So, the logic is-if we eat less meat, they will remove fewer forests!..." Interviewee A explicitly expressed that nature is God's creation, mankind should feel guilty of doing harms to God's gifts, and protecting the nature is part of God's command, which she should follow. In this regard, her pro-ES acts are extrinsic motivated, that means, she did them not for task-orientated happiness or satisfaction. Views on HC-ES relationship. Interviewee A confessed that she had never associate $\mathrm{HC}$ and ES together before the interview. When asked to think about HC-ES relationship on the spot, her view was found being close to no ideas at all. To her, their relationships were rather weak, and thus she was indifferent toward the integration of HC-ES. She explained in this way: "In my personal daily life, creativity and environmental protection had no relations... I would think about saving water in cooking, but this is nothing to do with creativity! Isn't it?..."

Views on HC-ES integrated education. Interviewee A commented that creativity was too abstract to her and she had no ideas on how to teach student creativity. Therefore, it was not surprising that she was not supportive to integrating creativity into ES education. However, at the end of the interview, her attitude seemed to be shaken a little. Although she did not support formal integration of HC-ES education, she recalled some creative environmental activities (e.g. making toys with up cycling materials in primary schools) that she came across in her teaching practice. At that moment, she spotted out one advantage of HC-ES integrated activities. She explained in this way: "I do not know how to teach creativity... yet, if really necessary to have creativity (education), I think creativity and ES can be taught together-one (reason) is to save time, the other is that creativity is just too abstract if teaching it alone." She commented that putting 
ES ideas to actions would be much more concrete than just considering some creative thoughts, and she seemed to believe that creative environmental activities may benefit student creativity development. Quite unexpectedly, her reason of integrated HC-ES education (if any) was not for the sake of better ES development, but for saving time and creativity!

\subsection{Case of Interviewee B}

Backgrounds. Interviewee B was a university student with similar backgrounds as that of Interviewee A. She reported that she learnt ES mostly from textbooks in secondary geography courses, and also from the courses of General Studies (her major) in the university. Unlike Interviewee A, Interviewee B minored in music. She used to play piano and always appreciated the creativity in music (but she herself was not keen in composition).

Views on $H C$. Interviewee B perceived creativity to be equivalent to "free imagination" (which is different from the practical problem solving in the function view of creativity). In her words, creativity mostly referred to something "unreal" and "free". In interview, she quite limited her creativity conception to the artistic or aesthetic endeavors. Concerning the level of creativity, her conception of creativity seemed also not that of common people, but more of professionals. For example, she tended to believe that only professional musicians with years of training can produce highly creative musical composition. Again, she did not consider herself as creative. Interviewee B seemed to hold a Prof-C conception of creativity.

Views on ES. When asked her views on ES, Interviewee B immediately related ES to the everyday "4Rs" (i.e. reduce, recycle, reuse and replace) which she learnt in her GS studies. She reported that she sometimes would try to save electricity in her university hostel, if at that moment she felt it convenient to do so. She described: "(when) it is very hot, I try to save electricity... [I do] not turn on air-conditioner, ...but (I) feel uncomfortable. "In follow-up discussion, she confessed that she did it not really for the Earth, but for the purpose of saving money which she described as a frugal virtue. To her, conflicts always happen in actualizing ES, and she expressed her pessimistic view in this way: "I think mankind cannot finally reach the goal set for ES. " At the societal level, Interviewee B thought the government had not done enough, and she urged them to do more for ES, such as teaching citizens more. She commented: "I feel the government can suggest more ways to do ES. Like me, I don't know any new ways for ES". Overall, Interviewee B did concern about ES, but she hold a rather pessimistic view on ES, inclined to a rule-following approach, and took the related actions based on extrinsic reasons (i.e. saving money).

Views on HC-ES relationships. Again, Interviewee B had not associate HC with ES before the interview. At first, she said she did not believe they had a strong relationship, but she changed her tone when she recalled something in her teaching practices. She elaborated in this way: "I guess, creativity may help to 
discover some ways to protect environment, such as reusing waste water...(in my teaching practice) I saw some primary students making a simple tool to purify waste water... Actually, some (existing) school activities are related to recycling or reuse of things. I know sometimes the teachers do let students design them... to make usable things from waste, but not always..." At the end of the interview, she concluded that sometimes HC might benefit ES, but her positive view could not be considered as a strong one. Interestingly, when asked directly what creativity is, Interviewee B expressed an aesthetic prof-C conception, however, when asked the relationship of HC and ES, her conception automatically shifted to little-C problem-solving creativity.

Views on HC-ES integrated education. In the second interview, Interviewee B said that she personally would not choose to teach creativity because she was not skillful in it. However, in a school education perspective, she supported that creativity development should be included in school curriculum, especially in the art-related subjects. In her words, students should not be limited, and should be allowed to think "out-of-the-box". When asked about the integration of HC and ES education, she simply said "good" and "why not" in a casual tone. However, in further discussion, she failed to explain why and could not make any concrete suggestion on this integrated education. She seemed had forgotten what she said in the first interview on how HC might benefit ES. And, it is uncertain how much her seemingly supportive view was affected the social desirability of creativity in the culture.

\subsection{Case of Interviewee C}

Backgrounds. Interviewee $\mathrm{C}$ is also a female university student with similar backgrounds as that of Interviewee A and B, except that she minored in creativity. When asked her most impressive ES learning experience, Interviewee $\mathrm{C}$ reported that she had chance to design and conduct environmental activities outside school/university. That means, she had important authentic ES learning experience. Views on $H C$. Interviewee $\mathrm{C}$ perceived creativity as something practically useful for solving everyday problems, as well as making life more interesting. Furthermore, she pursued creative process as a happy experience with internal satisfaction. It seems that her creative acts is self-actualizing. She reported that she could now and then integrate creativity into her daily life, for example, she had used her creativity to design activities for an environmental carnival. Drawing these feedbacks together, Interviewee $\mathrm{C}$ seemed to possess a Little-C and Mini-C conception of creativity.

Views on ES. Like Interviewee A and B, Interviewee $\mathrm{C}$ was also highly concerned about ES. She considered ES as to construct a better future for our next generation. To her, nature conservation could co-exist with business and other social values. Yet, she did not believe that following some simple rules can realize ES, and, to her, ES practices can be amazing, full of variations and fun. For example, she could quote some attractive litter bin designs that boosted recy- 
cling, and a cafe which collected old books and shared them among customers. She expressed her excitement when talking about these creative ES practices. Obviously, Interviewee C possessed a creative view to the realization of ES and possessed intrinsic motivation to pursue herself-determined pro-ES practices.

Views on HC-ES relationships. Obviously, Interviewee C was not so unprepared when asked what relationships HC and ES have. She could respond to the question quite quickly. She stressed that creativity was a tool for promoting and actualizing ES: "creativity helps us to think of more ways to reduce wastes and sustain the environment". She gave an example, “...(manufacturers) should think more carefully in production... using creativity to make the products to last longer...". Resembling Interviewee A and Interviewee C saw ES as more tangible and $\mathrm{HC}$ as thoughts that mainly stay on ideas. She commented: "creativity become more feasible by practicing ES'. To her, HC and ES are mutually enhancing.

Views on HC-ES integrated education. Interviewee C perceived ES education as one for developing students' social responsibility and competence to solve the human-earth problems. At the same time, she also committed in encouraging her students to think creatively and unleashing their innate creativity. Both of her views on HC education and ES education are emphasizing personal growth and self-actualization. It is not surprising that Interviewee $\mathrm{C}$ directly admitted her support on the HC-ES integrated education. In her words, "HC serves as the tool to get the solutions, whereas ES problems provide the places or needs... "It seemed that, to her, HC and ES education are inherently mutual enhancing with no conflicts or tensions-fully optimistic!

\subsection{Case of Interviewee D}

Backgrounds. Interviewee D's backgrounds were similar to that of Interviewee C (majored in General Studies and minored in Creativity), except that Interviewee $\mathrm{D}$ had working experiences in design for three years, before joining the education university. For the same reason, she was three years older than the other interviewees. On the whole, the views of Interviewee D resembled that of Interviewee $\mathrm{C}$, with a number of deviations which were reported below.

Views on HC. Interviewee D confessed that she was quite committed in creativity pursuit. She used to closely observe the media advertisement and was particularly interested in the creativity in TV commercials. She could recall excitedly many creative ideas in daily-life, for example, creative ideas in cake/bun making, their wrapping, their looks, and etc. When asked, she elaborated creativity conception explicitly like this: "There are many ways of interpreting creativity. Not only something out of nothing, it could be a modification from something existing before and could be something totally new. In my mind, formulating a new way of problem solving certainly is creativity too." Interviewee D had developed her own definition of creativity and also certain level of metacognition in creativity (Kaufman \& Beghetto, 2013b; Kaufman et al., 2016). Her reporting 
of creativity in everyday items and her habit of observing creativity in everyday settings reflected that she possessed Little- $\mathrm{C}$ and Mini-C conception of creativity.

ES Views. Interviewee D had deep concerns about ES too. Her view about sustainability emphasized on balancing all aspects of society and ecology. She reported that she deliberately practiced 4 Rs everyday and showed her deep concern about the neglect of ecological balance in China, through her strong critique on China governments and factories in the interview. Her view of achieving ES is not as optimistic as that of Interviewee C.

Views on HC-ES relationships. In the views of Interviewee D, HC and ES can both harm and help each other, and they have complicated relationships. In her words, creativity causes negative effects on environment, when people design many new fashions for different seasons and as a result created a lot of wastes which are detrimental to the environment. In opposite, adopting creative approach to teach ES can raise students' motivation, and train students to think creatively for environmental protection, which would ultimately help our society. In short, she thought that integrating creativity training into ES education is good, but creative products sometimes (e.g. seasonal fashion changes) can be harmful to the environment. On the other hand, she thought that strict emphasis on ES may hurt HC development too. She criticized, "sometimes, (creative) ideas may be killed because of its potential harmfulness to the environment." One example she quoted: "once there is a good proposal of redesigning the land-use of a man-made pond. But, it may involve killing the living things in the pond, the proposal is given up because of sustainability.....And, in fact, trying out creative ideas in arts, designs and even sciences will always create a lot of wastage, especially when they are not successful! ...." She concluded that potential damages to the environment may stop creative ideas from further development, that means, sustainability may constraint creative pursuits. To her, HC and ES can be mutually enhancing and also mutually hindering, depending on the contents and contexts.

Views on HC-ES education. Interviewee D supported HC education, ES education and also their integration. To demonstrate her strong favor to creativity education, she quoted her case of deliberately infusing creative thinking elements in teaching GS in her teaching practice in primary school. She reported she had also self-designed brainstorming exercises around ES issues (e.g. global warming). That means, she had already put creative environmental learning into practice, not a show of positive opinion. Yet, she reminded us that we need to be careful in integrating HC and ES education. She elaborated this point in a long and messy, but still understandable way. She first quoted the traditional Chinese philosophy of Yin-Yan balance to introduce her "middle path" approach of integration of HC-ES education. She then described: “... (HC and ES education should) sometimes integrated, sometimes separated...; (in integration, teachers) should not over-promote creativity, which may create unnecessary consumerism 
and harms to environment..., nor over-emphasize ES, which may put too much constraints on creativity development...; i.e. avoid the two extremes". She further commented that knowledge and value learning are also important to ES education-we need to seek balance among all aspects. To her, integration of creativity and ES education was not something simple, yet, if done in mindful way, it could create synergies to both developments of students. All these marvelous feedbacks are unexpected at the beginning of this study. University student $\mathrm{D}$ was found to possess exceptionally thoughtful and differentiated views on HC, ES, HC-ES integration and their education!

\subsection{Summary of the Four Cases}

The views of the four university students on HC, ES, HC-ES relationships and HC-ES integrated education were listed in Table 1.

Views on $H C$. The interview data revealed that the four interviewees had diverse views on what creativity is. Interviewee $\mathrm{A}$ took a Big- $\mathrm{C}$ conception and Interviewee B took a Prof- $C$ conception, whereas Interviewee $C$ and D had Little- $C$ and Mini- $\mathrm{C}$ conception of creativity and tended to consider creativity as a kind of self-actualization. In fact, this is the partial reason why these four samples were chosen in this report. A and B identified themselves as "not a creative person" or "do not have creativity". It is not surprising that they had not thought of "being creative" in their everyday life or in environmental practices, whereas C and $\mathrm{D}$ were more committed in creative pursuits. It seems that their conceptualizations were related to their personal backgrounds in creativity. Interviewee $\mathrm{A}$ and $\mathrm{B}$ had limited experiences and learnings in creativity, whereas Interviewee $\mathrm{C}$ and $\mathrm{D}$ were minored in creativity.

Views on ES. Though all interviewees demonstrated positive attitudes (concerns and values) towards ES, they hold diverse views on what ES is and on how to achieve ES. Interviewee A related her vegetarian life style to the current trend of ES practices. Interviewee B practiced 4Rs (e.g. saving electricity) at her convenience. Interviewee $\mathrm{C}$ and $\mathrm{D}$ referred $\mathrm{ES}$ to constructing a better future for our next generation. A and D's conception aligned more with that of sustainability (balance of environmental, economic and social development), whereas B and C were more concerned about $4 \mathrm{Rs}$ in environmental protection. Due to beliefs in God or human creativity, A and C were more optimistic to realizing ES, whereas B and $\mathrm{D}$ saw the dilemma and conflicts of mankind in solving ES problems. For achieving ES, A and B believed in the rule-following approach, whereas $\mathrm{C}$ and $\mathrm{D}$ took a more creative approach (i.e. self-finding ways to actualize $\mathrm{ES}$ ). Both $\mathrm{A}$ and $\mathrm{B}$ engaged in pro-ES behaviors for extrinsic reasons (i.e. God's faith and saving money). In contrast, the creative ES approach of $\mathrm{C}$ and $\mathrm{D}$ had brought them some intrinsic motivation in achieving ES (i.e. for task interest and self-satisfaction). In the self-determination theory, intrinsic motivation is crucial to developing self-initiated long-term behaviors. The self-actualizing and exciting process of pro-ES behaviors created intrinsic motives to $C$ and D to pursue ES. May be due 
to this reason, $\mathrm{C}$ and $\mathrm{D}$ took a more dynamic, proactive and forward-looking approach to ES.

Views on HC-ES relationships. Since the four university students had diverse views on $\mathrm{HC}$ and ES, it is rather natural that they also had different views on HC-ES relationships. Apart from taking different minor studies, their other backgrounds might also have affected their views. A and B mainly studied ES in formal curriculum, whereas $\mathrm{C}$ and $\mathrm{D}$ had more authentic experiences in ES and/or HC. In result, A and B perceived weak to nil relationships of $\mathrm{HC}$ and ES, whereas, the integration of $\mathrm{HC}$ and $\mathrm{ES}$ in daily-life was reported by $\mathrm{C}$ and $\mathrm{D}$ (i.e. C had observed some creativity in ES, while D had practiced creativity in ES in daily-life before the interviews). Comparatively, D took more differentiating and complicated views than $\mathrm{C}$. Cmerely perceived a strong mutually enhancing relationships of HC and ES developments, whereas D perceived both mutually enhancing and hindering relationships of $\mathrm{HC}$ and ES, depending the contents and contexts they were involved.

Views on HC-ES integrated education. Prior learning and daily-life experiences had exerted influences on interviewees' views on their capability of teaching HC and ES. All four university students had showed certain levels of confidence and commitment in teaching ES to their students, but not the same to teaching creativity. A and B did not have confidence nor intention to teach creativity. The reasons were made clear in their creativity conceptions. A and B hold Big-C and Prof-C conception of creativity respectively. They perceived creativity as too difficult or abstract to them. Teaching creativity seems to be out of the comfort zone of university students if they received no prior creativity training. Yet, quite unexpectedly, nearly all four university students supported the integration of $\mathrm{HC}$ and ES education, but to a very different degree. Based on their different beliefs on HC-ES relationships, $C$ was most optimistic and supportive to creative environmental education, whereas $\mathrm{D}$ demonstrated a most differentiated and thoughtful view on HC-ES integration education. D's exceptionally indepth understanding of HC-ES were related to her strong authentic experiences and metacognitive development in creativity. Comparatively, A and $B$ showed much lower support and understanding to HC-ES integrated education.

\section{Discussion}

\subsection{Summary of Findings}

The views of the university students were found to more complicated and diversified than we first expected. The particular findings of this study explicate university students' thoughts on creativity and sustainability. It revealed that some university students are totally unaware of the existence of a close relationship between HC and ES; they adopt Big-C or Prof-C conception of creativity and practice pro-ES behaviors by following external rules and based on extrinsic motivations (Interviewee A and B are the representatives). In contrast, university 
students having prior training in creativity and authentic creative/ES experiences tend to adopt Little- $\mathrm{C}$ and Mini-C conception of creativity, exhibit a creative approach to ES practices, demonstrate self-motivated and self-determined pro-ES behaviors, and also tend to be more positive to HC-ES integrated education(Interviewee $\mathrm{C}$ and $\mathrm{D}$ are the representatives). This study has thus far discovered that personal backgrounds, which include creativity training and related authentic experiences, affects the views of the university students on HC and ES, which in turn affect their confidence in teaching creativity in ES and also their supportiveness and understanding of creative environmental education.

\subsection{Lack of Creativity Education}

Environmental sustainability (ES) is a critical constituting element in everyday life and nowadays is an important education subject. Many ES relevant topics have been included into local school curriculum, integrated into General Studies and other subjects. In contrast, creativity training is rare in both school and university education. It is not surprising then the university students in our study were more confident in teaching ES than teaching creativity. Without a positive view or confidence in teaching creativity, it is difficult for university students (especially student teachers) to support and understand the significance and the feasibility of HC-ES integrated education. This study revealed that general creativity training or real-life creative/environmental experiences of university students are crucial to set out for creative ES education.

Though literature (discussed in earlier section) had well-documented the relationships of creative process and intrinsic motivation, however, the close relationship between consumerism and affinity to creative products, especially in young people, was also highlighted (Farro, 1982). As Brown \& Kasser (2005) revealed, an intrinsic value orientation in ES practices and a lifestyle of voluntary simplicity are both conducive to personal well-being and pro-ES behaviors. Therefore, HC and ES were not of a simple mutual-enhancing relationship, but were expected to be multi-faceted and complicated. Apart from idea-generation training, creativity education should go further to involve evaluative and ethical thinking, so as to develop indepth and differentiated views on HC and ES.

\subsection{Conceptions of Creativity}

This study revealed that, to some university students (e.g. Interviewee A and B), creativity was defined in a limited sense, biased toward genius or expert level. They definitely lacked a developmental framework of creativity as that suggested in Beghetto \& Kaufman (2014). With limited understanding and learning of creativity, university students may not know that creativity has Little-C level (i.e. everyday expressions of creativity) and as well as Mini-C level (i.e. subjective self-discoveries/insights in the learning process). The full conception of creativity is important to ES development. Everyday problem solving in ES practices (e.g. finding personal ways to replace a plastic bag or using less water in a bath) 
is a kind of Little-C creativity. Whereas, Mini- $\mathrm{C}$ is "a catalyst" for creative achievement-it is based on personal judgments, independent of external reference, and it signifies one's creative potential for higher levels of creativity development (Kaufman \& Beghetto, 2013a). According to results of Cheng (2016), the participants will re-conceptualize creativity to include Little- $\mathrm{C}$ and Mini-C level, if they have chance to engage in embodied creativity training in daily-life domains (Figure 1).

\subsection{Intrinsic Motivation and Self-Efficacy}

According to self-determination theory, for individuals to be able to perform life-long self-initiated pro-ES behaviors, they need to develop personal interests and intrinsic motivations in ES practices. A related theory (Deci et al., 1991; Baard et al., 2004) further suggested that if ones' psychological need of competence, autonomy and social-relatedness are fulfilled in certain practices, then their intrinsic motivation in those practices will be developed. If a person who performs the pro-ES behaviors based on guilt feeling or other extrinsic reasons, the action (Karaarslan et al., 2013) like the feedback of the participant A and B provided in the interviews. Echoed with these theories, this study revealed that, like university student $C$ and $D$, if persons adopta creative approach (in opposite to rule-following approach) to pro-ES practices, then their ES acts will be self-actualizing, full of excitement, and so promote a feeling of competence and autonomy, which will consequently foster a strong intrinsic motivation in their ES pursuits. The intrinsic motivation to perform pro-ES behaviors can be manifested in the following interview scrip of university student $\mathrm{C}$ :

University student $C$ : Being creative in them (the $4 R$ s practices) made me enjoying the activity because being able to do it basically proved myself... Y eah! I could make something useful and interesting, despite the restrictions... (The feeling is) sort of like meeting a challenge... it is a kind of personal satisfactionovercoming the constraints.

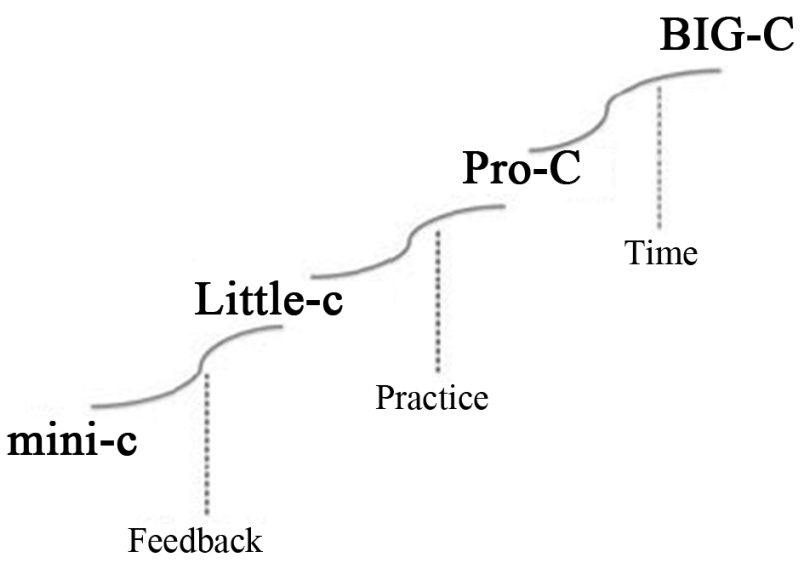

Figure 1. The developmental trajectory of creativity. (Extracted from Beghetto \& Kaufman (2014). Classroom Contexts for Creativity, p. 55). 
Participant D: I think I am about 70\% (a creative person) because I like brainstorming some weird and crazy ideas. I do not like boring things at al! In secondary school, I am not so, but when I work outside, I open myself to try a lot of new things. They inspired me that I can be creative...

Some past studies revealed that if people perceive themselves as creative persons, they would be more open to new experiences (King et al., 1996; McCrae, 1987; Silvia et al., 2009a; Silvia et al., 2009b). In reverse, people who are more open to new experience would be more creative and develop higher interest in creative pursuits (Silvia et al., 2009b; Silvia et al., 2014). In this study, the interview scripts of Participant D (see above) illustrated this point well. Both university student $\mathrm{C}$ and $\mathrm{D}$ recognized themselves as a creative person and expressed their confidence in pursuing creativity. They demonstrated their creative self-efficacy and intrinsic motivation in actualizing ES and their favor in teaching creative environmental education. Moreover, in the long run, we expected their creative ES practices will in turn strengthen their creative self-efficacy and nourish back their creativity. The reciprocal relationship of these endeavors is significant to the whole issue. As university student $\mathrm{C}$ and D speculated, HC and ES development can be in synergy, mutually enhancing each other.

\subsection{Limitations of This Study}

The first limitation comes from the sampling method. Purposive sampling is typically used in qualitative research to identify and select the information-rich cases to fulfill the specific research objectives (Etikan et al., 2016). Although it is the best use of available resources, critics argue that this kind of sampling will have an inherent potential for bias (Bogdan \& Biklen, 2006) caused by the non-random selection. In the case studies of the present research, in order to obtain wide and meaningful views of university students, the selected respondents must have the following particular characteristics to fulfill the research requirements: coming from a place of diverse cultures, studying subject major related to environmental education, had some teaching practices in schools, and yet had differences in their learning and experience backgrounds for comparison. However, they had the same gender-all are females. In this way, any differences emerged in the case studies are surely unrelated to gender, but related to other backgrounds and experiences of the respondents. Moreover, the sample of the present study were all students in education programme. They were purposely chosen because students in education programmes were more concern about environmental education.

The second limitation is caused by the specific context for conducting this study. As this study was undertaken in Hong Kong, thus the interpretation of findings is limited to Hong Kong context. Of course, university student views are likely to be influenced by their cultural and educational backgrounds. However, it is impossible to reveal all possible views on HC and ES by a single study. In order to gain a broader and more dynamic understanding of the issue, this study 
had chosen a context of mixed east-west cultures with on-going educational changes to conduct the research. As elaborated in prior sections, the diverse and in-depth case study results had already brought meaningful inspirations to the academic field. For generalization of the results, future studies which apply the method of the present study to other cultural and ethnic contexts, are called for.

The third limitation comes from the interview study method. Before tapping their views on HC-ES integrated education, university students were asked about their views on HC, ES and HC-ES relationships. It is difficult to avoid the priming effects of early questions on answers of later questions. To reduce this possible priming effect, two interviews scheduled one month apart were conducted on each university student. Furthermore, we need to admit that creativity is always highly appraised in the local culture. It is unsure whether the university students' reported views on integrated creativity into ES education were influenced by the social desirability of creativity (like that reported by Interviewee A and B). To understand more solid meanings of their reported views, university students were further asked to elaborate views, including explaining why they had these views and suggesting how HC and ES education can be integrated

\subsection{Contributions and Remarks}

The present study discovered that university students without authentic learning experiences in creativity and/or ES may not aware of the role of creativity in ES and may not support the development of creativity in ES. On the contrary, general creativity training and the developed little-C conception of creativity can enhance students' support of HC-ES integration, and their self-determined, intrinsic-motivated ES behaviors.

As suggested by the respondents of this study, human creativity (HC) can motivate and empower environmental/sustainable (ES) practices, and vice versa. Inspired by the results of this study, future university education needs to find ways to promote students' creative view and intrinsic motivation in ES, and to enhance their understanding of HC, ES and HC-ES relationships. It is hoped that, in the near future, creativity and its relevant general training can occupy a substantial part in university education curriculum, which would benefit not only ES education but also facilitate creative development in all domains. Academic researches and curriculum studies are called for to further explore the development of creative environmental/sustainable curriculum so as to produce synergetic effects to both HC and ES developments. Ultimately, we look forward to an education system that promotes life-long self-determined self-motivated sustainable development to our next generation.

\section{Acknowledgements}

Thanks to the funding support of Dean's Research Fund of Education University of Hong and Kong, and the research support of Miss Li Wing Ling and Dr. Mabel Chan. Thanks are also extended to all the participants of this study. 


\section{References}

Albrechts, L. (2010). How to Enhance Creativity, Diversity and Sustainability in Spatial Planning: Strategic Planning Revisited. Urban and Landscape Perspectives, 9, 3-25. https://doi.org/10.1007/978-90-481-3106-8_1

Amabile, T., Barsade, S., Mueller, J., \& Staw, B. (2005). Affect and Creativity at Work. Administrative Science Quarterly, 50, 367-403. https://doi.org/10.2189/asqu.2005.50.3.367

Baard, P. P., Deci, E. L., \& Ryan, R. M. (2004). Intrinsic Need Satisfaction: A Motivational Basis of Performance and Well-Being in Two Work Settings. Journal of Applied Social Psychology, 34, 2045-2068. https://doi.org/10.1111/j.1559-1816.2004.tb02690.x

Barbier, P. Y., Pruneau, D., \& Langis, M. (2009). Unfolding Being-with-Environment through Creative Problem Solving in Environmental Education. International Journal of Learning, 16, 499-510. https://doi.org/10.18848/1447-9494/CGP/v16i02/46142

Bechtel, R. B., \& Corral-Verdugo, V. (2010). Happiness and Sustainable Behavior. In V. Corral-Verdugo, C. Garc1'a, \& M. Fr'’as (Eds.), Psychological Approaches to Sustainability (pp. 433-450). New York, NY: Nova Science Publishers.

Beghetto, R. A. (2010). Creativity in the Classroom. In R. J. Sternberg, \& J. C. Kaufman (Eds.), The Cambridge Handbook of Creativity (pp. 447-463). Cambridge: Cambridge University Press. https://doi.org/10.1017/CBO9780511763205.027

Beghetto, R. A., \& Kaufman, J. C. (2007). Toward a Broader Conception of Creativity: A Case for "mini-c" Creativity. Psychology of Aesthetics, Creativity, and the Arts, 1, 73-79. https://doi.org/10.1037/1931-3896.1.2.73

Beghetto, R. A., \& Kaufman, J. C. (2014). Classroom Contexts for Creativity. High Ability Studies, 25, 53-69. https://doi.org/10.1080/13598139.2014.905247

Bogdan, R. C., \& Biklen, S. K. (2006). Ch. 2: Research Design. In Qualitative Research in Education: An Introduction to Theory and Methods (pp. 58-78). Boston: Allyn \& Bacon.

Brown, K. W., \&Kasser, T. (2005). Are Psychological and Ecological Well-Being Compatible? The Role of Values, Mindfulness, and Lifestyle. Social Indicators Research, 74, 349-368.

Chang, J. W., Hwang, W., \& Choi, J. N. (2012). Is Task Autonomy Beneficial for Creativity? Prior Task Experience and Self-Control as Boundary Conditions. Social Behavior and Personality, 40, 705-724. https://doi.org/10.2224/sbp.2012.40.5.705

Cheng, V. M. Y. (2010). Tensions and Dilemmas of Teachers in Creativity Reform in a Chinese Context. Thinking Skills and Creativity, 5, 120-137. https://doi.org/10.1016/j.tsc.2010.09.005

Cheng, V. M. Y. (2011). Infusing Creativity into Eastern Classrooms: Evaluations from Student Perspectives. Thinking Skills and Creativity, 6, 67-87. https://doi.org/10.1016/j.tsc.2010.05.001

Cheng, V. M. Y. (2016). Understanding and Enhancing Personal Transfer of Creative Learning. Thinking Skills and Creativity, 22, 58-73. https://doi.org/10.1016/j.tsc.2016.09.001

Clemente, M. (2009). De-Globalization and Creativity: A Contribution towards Sustainable and Intercultural Architectures and Cities. International Journal of Sustainable Development, 12, 116-123. https://doi.org/10.1504/IJSD.2009.032772

Corbin, J. M., \& Strauss, A. L. (2008). Criteria for Evaluation. In J. M. Corbin, \& M. L. Strauss (Eds.), Basics of Qualitative Research: Techniques and Procedures for Developing Grounded Theory (pp. 297-313, 3rd ed.). Thousand Oaks, CA: Sage publications. 
https://doi.org/10.4135/9781452230153.n14

Corbin, J. M., \& Strauss, A. L. (2015). Basics of Qualitative Research: Techniques and Procedures for Developing Grounded Theory ( $4^{\text {th }}$ ed.). Thousand Oaks, CA: Sage publications.

Corral-Verdugo, V. (2012). The Positive Psychology of Sustainability. Environment, Development \& Sustainability, 14, 651-666. https://doi.org/10.1007/s10668-012-9346-8

Corral-Verdugo, V., Bonnes, M., Tapia-Fonllem, C., Fraijo-Sing, B., Frias-Armenta, M., \& Carrus, G. (2009). Correlates of Pro-Sustainability Orientation: The Affinity towards Diversity. Journal of Environmental Psychology, 29, 34-43.

https://doi.org/10.1016/j.jenvp.2008.09.001

Corral-Verdugo, V., Tapia-Fonllem, C., \& Ortiz-Valdez, A. (2015). On the Relationship between Character Strengths and Sustainable Behavior. Environment and Behavior, 47, 877-901. https://doi.org/10.1177/0013916514530718

Craft, A. (2001). Little C Creativity. In A. Craft, B. Jeffrey, \& M. Leibling (Eds.), Creativity in Education (pp. 45-61). New York, NY: Continuum International.

Creswell, J. W. (2015). Ch. 14: Ethnographic Designs. In Educational Research: Planning, Conducting, and Evaluating Quantitative and Qualitative Research, Enhanced Pearson eText with Loose-Leaf Version-Access Card Package (5th ed., pp. 465-502). London: Pearson Education.

Csikszentmihalyi, M. (1996). Ch. 3: The Creative Personality. In Creativity: Flow and the Psychology of Discovery and Invention (pp. 51-76). New York, NY: Harper Collins Publishers.

Darner, R. (2009). Self-Determination Theory as a Guide to Fostering Environmental Motivation. The Journal of Environmental Education, 40, 39-49.

https://doi.org/10.3200/JOEE.40.2.39-49

Darner, R. (2012). An Empirical Test of Self-Determination Theory as a Guide to Fostering Environmental Motivation. Environmental Education Research, 18, 463-472. https://doi.org/10.1080/13504622.2011.638739

Daskolia, M., \& Kynigos, C. (2012). Applying a Constructionist Frame to Learning about Sustainability. Creative Education, 3, 818-823. https://doi.org/10.4236/ce.2012.326122

Daskolia, M., Dimos, A., \& Kampylis, P. G. (2012). Secondary Teachers' Conceptions of Creative Thinking within the Context of Environmental Education. International Journal of Environmental \& Science Education, 7, 269-290.

Davis, E. A., \& Krajcik, J. S. (2005). Designing Educative Curriculum Materials to Promote Teacher Learning. Educational Researcher, 34, 3-14. https://doi.org/10.3102/0013189X034003003

De Groot, J. I., \& Steg, L. (2010). Relationships between Value Orientations, Self-Determined Motivational Types and Pro-Environmental Behavioural Intentions. Journal of Environmental Psychology, 30, 368-378. https://doi.org/10.1016/j.jenvp.2010.04.002

Deci, E. L., \& Ryan, R. M. (2008). Facilitating Optimal Motivation and Psychological Well-Being across Life's Domains. Canadian Psychology, 49, 14-23. https://doi.org/10.1037/0708-5591.49.1.14

Deci, E. L., Vallerand, R. J., Pelletier, L. G., \& Ryan, R. M. (1991). Motivation and Education: The Self-Determination Perspective. Educational Psychologist, 26, 325-346. https://doi.org/10.1080/00461520.1991.9653137

Disinger, J. F. (1990). Environmental Education for Sustainable Development? Journal of Environmental Education, 21, 3-6. https://doi.org/10.1080/00958964.1990.9941931 
Esa, N. (2010). Environmental Knowledge, Attitude and Practices of Student Teachers. International Research in Geographical and Environmental Education, 19, 39-50. https://doi.org/10.1080/10382040903545534

Etikan, I., Musa, S. A., \& Alkassim, R. S. (2016). Comparison of Convenience Sampling and Purposive Sampling. American Journal of Theoretical and Applied Statistics, 5, 1-4. https://doi.org/10.11648/j.ajtas.20160501.11

Farro, A. (1982). Young People, Creativity, and Consumerism. Sociologia Del Lavoro, 5, 39-48.

Foster, J. (2011). Sustainability and the Learning Virtues. Journal of Curriculum Studies, 43, 383-402. https://doi.org/10.1080/00220272.2010.521260

Fraj, E., \& Martinez, E. (2006). Environmental Values and Lifestyles as Determining Factors of Ecological Consumer Behaviour: An Empirical Analysis. Journal of Consumer Marketing, 23, 113-144. https://doi.org/10.1108/07363760610663295

Fretwell, H. (2009). Environmental Education: The Science of Fear. PERC Reports, 27, 8-11.

Glaveanu, V. P. (2011). Is the Lightbulb Still on? Social Representations of Creativity in a Western Context. The International Journal of Creativity \& Problem Solving, 21, 53-72.

Gray, P., Elser, C. F., Klein, J. L., \& Rule, A. C. (2016). Literacy and Arts-Integrated Science Lessons Engage Urban Elementary Students in Exploring Environmental Issues. Science Education International, 27, 151-175.

Hedlund-de Witt, A., De Boer, J., \& Boersema, J. J. (2014). Exploring Inner and Outer Worlds: A Quantitative Study of Worldviews, Environmental Attitudes, and Sustainable Lifestyles. Journal of Environmental Psychology, 37, 40-54.

https://doi.org/10.1016/j.jenvp.2013.11.005

Hines, J. M., Hungerford, H. R., \& Tomera, A. N. (1987). Analysis and Synthesis of Research on Responsible Environmental Behavior: A Meta-Analysis. Journal of Environmental Education, 18, 1-8. https://doi.org/10.1080/00958964.1987.9943482

Homfray, E. (2012). Having Creative Fun within the Environment. Environmental Education, 100, 19.

Hui, A. N. N., \& Lau, S. (2010). Formulation of Policy and Strategy in Developing Creativity Education in Four Asian Chinese Societies: A Policy Analysis. Journal of Creative Behavior, 44, 215-235. https://doi.org/10.1002/j.2162-6057.2010.tb01334.x

Hui, A. N. N., He, M. W., \& Ye, S. S. (2015). Arts Education and Creativity Enhancement in Young Children in Hong Kong. Educational Psychology, 35, 315-327. https://doi.org/10.1080/01443410.2013.875518

Iannarone, S. S. (2008). Planning for Sustainability: Cultivating Wisdom and Creativity in Practice and Theory. http://citeseerx.ist.psu.edu/viewdoc/download?doi=10.1.1.487.9576\&rep=rep1\&type=pdf

Jindal-Snape, D., Davies, D., Collier, C., Howe, A., Digby, R., \& Hay, P. (2013). The Impact of Creative Learning Environments on Learners: A Systematic Literature Review. Improving Schools, 16, 21-31. https://doi.org/10.1177/1365480213478461

Karaarslan, G., Ertepinar, H., \& Sungur, S. (2013). Use of Self-Determination Theory to Support Basic Psychological Needs of Preservice Science Teachers in an Environmental Science Course. Environmental Education Research, 19, 342-369. https://doi.org/10.1080/13504622.2012.695013

Karaarslan, G., Sungur, S., \& Ertepınar, H. (2014). Developing Preservice Science Teachers' Self-Determined Motivation toward Environment through Environmental Activities. International Journal of Environmental \& Science Education, 9, 1-19. 
Kaufman, J. C., \& Beghetto, R. A. (2009). Beyond Big and Little: The Four C Model of Creativity. Review of General Psychology, 13, 1-12. https://doi.org/10.1037/a0013688

Kaufman, J. C., \& Beghetto, R. A. (2013a). Do People Recognize the Four Cs? Examining Layperson Conceptions of Creativity. Psychology of Aesthetics, Creativity, and the Arts, 7, 229-236. https://doi.org/10.1037/a0033295

Kaufman, J. C., \& Beghetto, R. A. (2013b). In Praise of Clark Kent: Creative Metacognition and the Importance of Teaching Kids When (not) to Be Creative. Roeper Review, 35, 155-165. https://doi.org/10.1080/02783193.2013.799413

Kaufman, J. C., Beghetto, R. A., \& Watson, C. (2016). Creative Metacognition and Self-Ratings of Creative Performance: A 4-C Perspective. Learning and Individual Differences, 51, 394-399. https://doi.org/10.1016/j.lindif.2015.05.004

King, L. A., Walker, L. M., \& Broyles, S. J. (1996). Creativity and the Five-Factor Model. Journal of Research in Personality, 30, 189-203. https://doi.org/10.1006/jrpe.1996.0013

Kuhlemeier, H., Van den Bergh, H., \& Lagerweij, N. (1999). Environmental Knowledge, Attitudes, and Behavior in Dutch Secondary Education. Journal of Environmental Education, 30, 4-14. https://doi.org/10.1080/00958969909601864

Levine, D. S., \& Strube, M. J. (2012). Environmental Attitudes, Knowledge, Intentions and Behaviors among College Students. Journal of Social Psychology, 152, 308-326. https://doi.org/10.1080/00224545.2011.604363

Lewis, T. (2012). There Grows the Neighbourhood: Green Citizenship, Creativity and Life Politics on Eco-TV. International Journal of Cultural Studies, 15, 315-326. https://doi.org/10.1177/1367877911433753

Maslow, A. (1968). Ch. 10: Creativity in Self-Actualizing People. In Toward a Psychology of Being (2nd ed., pp. 135-145). New York, NY: Van Nos/Trand Reinhold Company.

McCrae, R. R. (1987). Creativity, Divergent Thinking, and Openness to Experience. Journal of Personality and Social Psychology, 52, 1258-1265. https://doi.org/10.1037/0022-3514.52.6.1258

Miles, M. B., \& Huberman, A. M. (1994). Ch. 4: Early Steps in Analysis. In Qualitative Data Analysis: An Expanded Sourcebook (2nd ed., pp. 50-89). London: Sage.

Ojala, M. (2012). Hope and Climate Change: The Importance of Hope for Environmental Engagement among Young People. Environmental Education Research, 18, 625-642. https://doi.org/10.1080/13504622.2011.637157

Otto, S., Neaman, A., Richards, B., \& Mario, A. (2016). Explaining the Ambiguous Relations between Income, Environmental Knowledge, and Environmentally Significant Behavior. Society \& Natural Resources, 29, 628-632. https://doi.org/10.1080/08941920.2015.1037410

Paletz, S., Kim, K., Schunn, C., Tollinger, I., \& Vera, A. (2013). Reuse and Recycle: The Development of Adaptive Expertise, Routine Expertise, and Novelty in a Large Research Team. Applied Cognitive Psychology, 27, 415-428.

https://doi.org/10.1002/acp.2928

Patton, M. Q. (2002). Two Decades of Developments in Qualitative Inquiry a Personal, Experiential Perspective. Qualitative Social Work, 1, 261-283. https://doi.org/10.1177/1473325002001003636

Pe'er, S., Goldman, D., \& Yavetz, B. (2007). Environmental Literacy in Teacher Training: Attitudes, Knowledge, and Environmental Behavior of Beginning Students. The Journal of Environmental Education, 39, 45-59. https://doi.org/10.3200/JOEE.39.1.45-59

Robinson, K., \& Azzam, A. M. (2009). Why Creativity Now. Educational Leadership, 67, 22-26. 
Runco, M. A., \& Jaeger, G. J. (2012). The Standard Definition of Creativity. Creativity Research Journal, 24, 92-96. https://doi.org/10.1080/10400419.2012.650092

Ryan, R. M., \& Deci, E. L. (2000). Self-Determination Theory and the Facilitation of Intrinsic Motivation, Social Development, and Well-Being. American Psychologist, 55, 68-78. https://doi.org/10.1037/0003-066X.55.1.68

Sandri, O. J. (2013). Exploring the Role and Value of Creativity in Education for Sustainability. Environmental Education Research, 19, 765-778. https://doi.org/10.1080/13504622.2012.749978

Sang, A. N. H. (2010). Plastic Bags and Environmental Pollution. Art Education, 63, 39-43.

Scoffham, S. (2013). Geography and Creativity: Developing Joyful and Imaginative Learners. Education, 41, 368-381. https://doi.org/10.1080/03004279.2013.819625

Sellman, E. (2012). Ch. 2: Creative Approaches to Inclusion. In E. Sellman (Ed.), Creative Learning for Inclusion: Creating Learning to Meet Special Needs in the Classroom (pp. 3-14). New York, NY: Routledge.

Silo, N., \& Khudu-Petersen, K. (2016). Hearing Ancestral Voices through Creative Art-A Tool for Environmental Education for Sustainability. International Journal of Education \& the Arts, 17, 1-21.

Silvia, P. J., Beaty, R. E., Nusbaum, E. C., Eddington, K. M., Levin-Aspenson, H., \& Kwapil, T. R. (2014). Everyday Creativity in Daily Life: An Experience-Sampling Study of "Little c" Creativity. Psychology of Aesthetics, Creativity, and the Arts, 8, 183-188. https://doi.org/10.1037/a0035722

Silvia, P. J., Kaufman, J. C., \& Pretz, J. E. (2009a). Is Creativity Domain-Specific? Latent Class Models of Creative Accomplishments and Creative Self-Descriptions. Psychology of Aesthetics, Creativity, and the Arts, 3, 139-148. https://doi.org/10.1037/a0014940

Silvia, P. J., Nusbaum, E. C., Berg, C., Martin, C., \& O’Connor, A. (2009b). Openness to Experience, Plasticity, and Creativity: Exploring Lower-Order, High-Order, and Interactive Effects. Journal of Research in Personality, 43, 1087-1090. https://doi.org/10.1016/j.jrp.2009.04.015

Sterling, S. (2009). Sustainable Education. In D. Gray, L. Colucci-Gray, \& E. Camino (Eds.), Science, Society and Sustainability: Education and Empowerment for an Uncertain World (pp. 105-118). New York, NY: Routledge.

Strife, S. J. (2012). Children's Environmental Concerns: Expressing Eco-Phobia. Journal of Environmental Education, 43, 37-54. https://doi.org/10.1080/00958964.2011.602131

Tabone, C. P. (2011). Environmental Education under Assault: Can Instructors Teach Environmental Science without Fear? Interdisciplinary Environmental Review, 12, 146-153. https://doi.org/10.1504/IER.2011.040245

Van der Werff, E., Steg, L., \& Keizer, K. (2013). It Is a Moral Issue: The Relationship between Environmental Self-Identity, Obligation-Based Intrinsic Motivation and Pro-Environmental Behaviour. Global Environmental Change, 23, 1258-1265. https://doi.org/10.1016/j.gloenvcha.2013.07.018 